\title{
Collagenous gastroduodenocolitis in a Korean adolescent: first pediatric case report in Asia
}

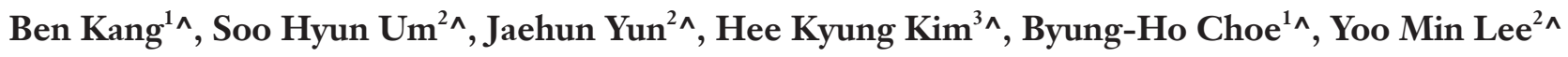 \\ ${ }^{1}$ Department of Pediatrics, School of Medicine, Kyungpook National University, Daegu, Republic of Korea; ${ }^{2}$ Department of Pediatrics, \\ Soonchunhyang University Bucheon Hospital, Soonchunhyang University College of Medicine, Bucheon, Republic of Korea; ${ }^{3}$ Department of \\ Pathology, Soonchunhyang University Bucheon Hospital, Soonchunhyang University College of Medicine, Bucheon, Republic of Korea \\ Correspondence to: Yoo Min Lee, MD, PhD. Department of Pediatrics, Soonchunhyang University College of Medicine, Bucheon 14584, Republic of Korea. \\ Email: flana@schmc.ac.kr.
}

\begin{abstract}
Collagenous gastritis (CG) is a rare disease diagnosed histologically by the subepithelial deposition of collagen bands thicker than $10 \mu \mathrm{m}$ and the infiltration of inflammatory mononuclear cells in the lamina propria. The definite pathophysiology is yet to be elucidated. However, recent studies have suggested that the collagen deposition may be the result of a reparative process in response to an earlier inflammatory, autoimmune, infectious, or toxic insult. CG is divided into the pediatric- and adult-type. While the pediatrictype is limited to the stomach, the adult-type involves not only the stomach but also the intestine and/or colon. We report a rare case of adult-type CG in a 15-year-old boy who initially presented with abdominal pain and iron-deficiency anemia. Esophagogastroduodenoscopy (EGD) revealed findings suspicious for Helicobacter pylori (H. pylori) gastritis. Although histology did not reveal the organism, campylobacter-like organism (CLO) test was positive. Based on the diagnosis of suspicious H. pylori gastritis, eradication was conducted using the triple drug regimen. However, symptoms of intermittent abdominal pain persisted and diarrhea newly developed one year later. Histologic results from biopsies from the stomach, duodenum, and colon revealed findings compatible with CG, collagenous duodenitis (CD), and collagenous colitis (CC). This is the first pediatric case of collagenous gastroduodenocolitis (CGDC) reported in Asia. It is no longer assumed that adult-type and pediatric-type CG should be classified as an independent disease, but should be considered as similar diseases on a continuous spectrum. Therefore, children and adolescents diagnosed with CG should also consider undergoing a colonoscopy for the evaluation of possible coexisting CC when concurrent lower gastrointestinal symptoms are present. Moreover, considering the possibility of negative findings on the first endoscopy, repeat endoscopy should be considered when symptoms persist.
\end{abstract}

Keywords: Case report; collagenous colitis (CC); collagenous duodenitis (CD); collagenous gastritis (CG); colonoscopy

Submitted Jul 25, 2021. Accepted for publication Sep 29, 2021.

doi: $10.21037 / \mathrm{tp}-21-342$

View this article at: https://dx.doi.org/10.21037/tp-21-342

\section{Introduction}

Collagenous gastritis (CG) is a rare disease diagnosed histologically by the subepithelial deposition of collagen bands thicker than $10 \mu \mathrm{m}$ in the lamina propria (1). The definite pathophysiology is not proven. However, there is a suggested hypothesis that collagen deposition may be the result of a reparative process in response to an earlier inflammatory, autoimmune, infectious or toxic insult (2-4).

\footnotetext{
^ ORCID: Ben Kang, 0000-0002-8516-9803; Soo Hyun Um, 0000-0001-5737-1898; Jaehun Yun, 0000-0001-6491-175X; Hee Kyung Kim, 00000002-7369-3827; Byung-Ho Choe, 0000-0001-9899-9120; Yoo Min Lee, 0000-0003-3554-6559.
} 

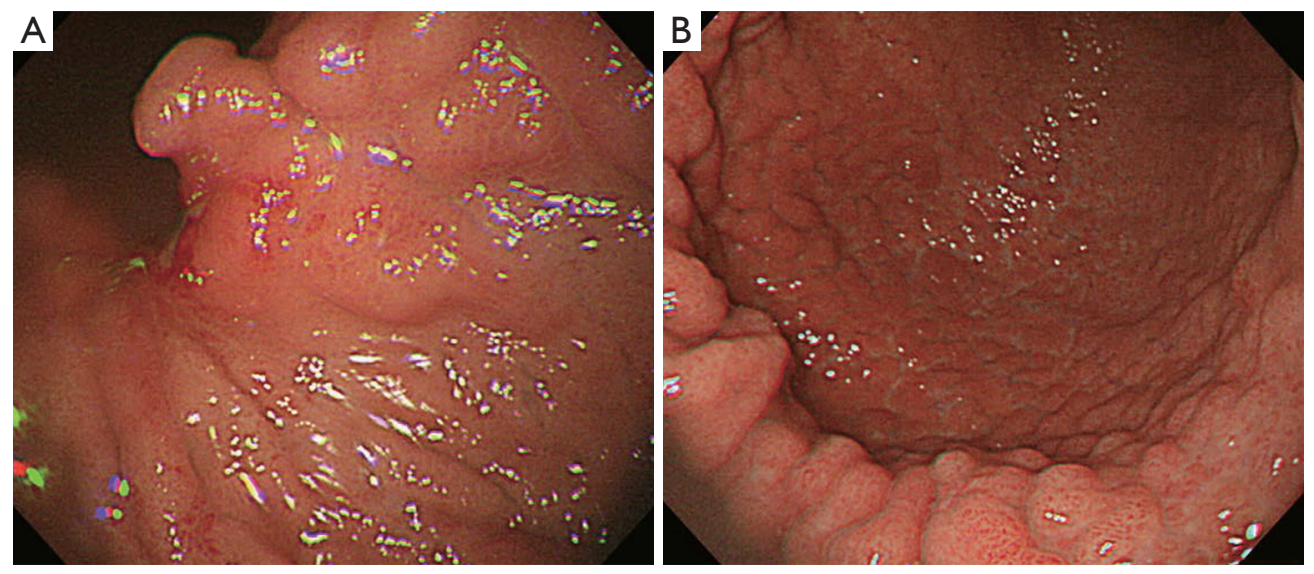

Figure 1 Medium to large sized gastric ulcers in the cardia with diffuse nodular hyperplasia were observed on EGD. EGD, esophagogastroduodenoscopy.

CG is divided into two phenotypes: pediatric- and adulttype. Involvement of the pediatric-type CG is confined to the stomach, while the adult-type CG has concurrent involvement in the small and/or large bowel. It is now acknowledged that adult-type and pediatric-type CG should not be classified as an independent disease, but should be considered as similar diseases on a continuous spectrum (5).

There are only few reports in literature of children and adolescents diagnosed as CG with concurrent collagenous duodenitis (CD) and/or collagenous colitis (CC) $(1,2,5-16)$. We present a rare pediatric case of collagenous gastroduodenocolitis (CGDC) in whom subepithelial deposition of thickened collagen bands were observed in the stomach, duodenum and colon.

We present the following case in accordance with the CARE reporting checklist (available at https://dx.doi. org/10.21037/tp-21-342).

\section{Case presentation}

A 15 -year-old boy was admitted due to chronic abdominal pain for one year. His abdominal pain was mainly epigastric, and it rapidly aggravated during fasting. Subsequently, unformed stool was observed for one month. Additionally, his weight had decreased from 49.6 to $47.6 \mathrm{~kg}$ (4 percentile) during a period of two weeks. His height was $168.8 \mathrm{~cm}$ (35 percentile) and his body mass index was $16.71 \mathrm{~kg} / \mathrm{m}^{2}$ ( 2 percentile). He had been diagnosed with IDA at 11-year-old and had been treated with oral iron supplements continuously. At that time, his hemoglobin level was $7.1 \mathrm{mg} / \mathrm{dL}$; hematocrit 25.0\%; white blood cell (WBC) count
5,010/ $\mu \mathrm{L}$; platelet count $465,000 / \mu \mathrm{L}$; iron $12 \mu \mathrm{g} / \mathrm{dL}$; ferritin $2 \mathrm{ng} / \mathrm{mL}$; total iron binding capacity (TIBC) $448 \mu \mathrm{g} / \mathrm{dL}$; transferrin saturation (TS) $2.7 \%$; total protein $6.7 \mathrm{~g} / \mathrm{dL}$; and albumin $4.1 \mathrm{~g} / \mathrm{dL}$.

On admission, there was no tenderness or rebound tenderness in the abdomen, and his bowel sound was normoactive. Other physical exams were unremarkable. Laboratory exams at admission showed hemoglobin $9.8 \mathrm{mg} / \mathrm{dL}$; hematocrit $32.9 \%$; WBC count $8,130 / \mu \mathrm{L}$; platelet count $357,000 / \mu \mathrm{L}$; iron $10 \mu \mathrm{g} / \mathrm{dL}$; ferritin $5 \mathrm{ng} / \mathrm{mL}$; TIBC $352 \mu \mathrm{g} / \mathrm{dL}$; TS $2.8 \%$; total protein $6.4 \mathrm{~g} / \mathrm{dL}$; albumin $3.9 \mathrm{~g} / \mathrm{dL}$; C-reactive protein (CRP) $0.25 \mathrm{mg} / \mathrm{dL}$; and erythrocyte sedimentation rate (ESR) $32 \mathrm{~mm} / \mathrm{h}$. His fecal immunochemistry test (FIT) was positive, and fecal calprotectin (FC) level was $573 \mathrm{mg} / \mathrm{kg}$. Other laboratory tests, including liver enzyme, thyroid function test, stool bacterial and virus antigen test were normal. Esophagogastroduodenoscopy (EGD) revealed diffuse mucosal nodularity and multiple large ulcers at the anterior portion of the cardia in the stomach (Figure 1). The diffuse nodular hypertrophic mucosa extended through the pylorus to the bulb and second portion of the duodenum. Colonoscopy was grossly normal. Histologic findings of biopsies from the stomach antrum, body, duodenum, and all segments of the colon revealed findings of chronic inflammation, and special stains were not conducted. Campylobacter-like organism (CLO) test was positive, and lansoprazole, amoxicillin, and clarithromycin were prescribed for two weeks to eradicate the suspected Helicobacter pylori (H. pylori) infection. Urea breath test, which was conducted six weeks later, was negative. There were no adverse events during eradication treatment of 

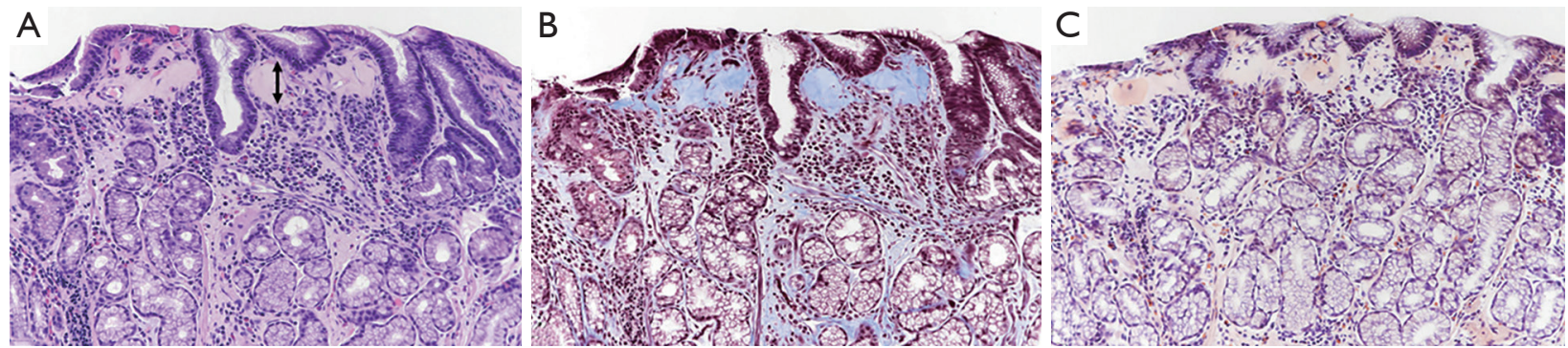

Figure 2 Microscopic images of the mucosal biopsy specimen from the stomach antrum. (A) A dense irregular eosinophilic band is noted below the gastric surface epithelium measuring $60 \mu \mathrm{m}$ (double headed arrow), and there is chronic inflammation in the lamina propria (H\&E, $\times 200)$. (B) The thickened subepithelial layer stain blue with Masson trichrome stain $(\times 200)$. (C) Congo red stains are negative ( $\times 200)$.

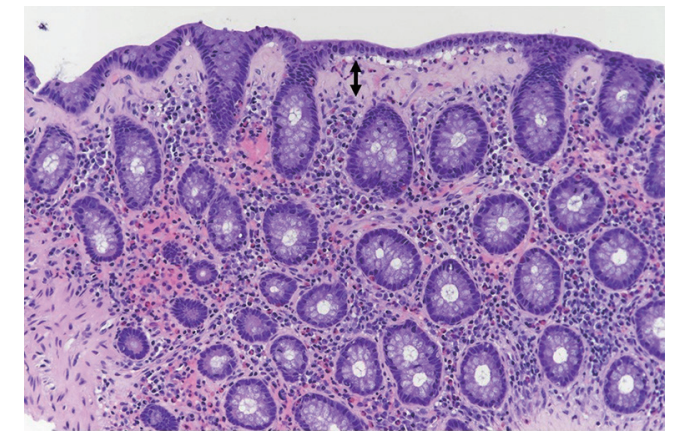

Figure 3 Histopathological examination of colon biopsy shows acellular collagenous dense bands (double headed arrow) underneath the epithelium, measuring $30 \mu \mathrm{m}$ in thickness (H\&E, $\times 200)$.

the suspected $H$. pylori infection. After treatment, his weight recovered within two weeks.

However, symptoms of intermittent abdominal pain persisted and diarrhea newly developed one year late. His IDA also did not improve, despite successful $H$. pylori eradication and continuous oral iron supplementation. Laboratory exams showed hemoglobin $9.3 \mathrm{mg} / \mathrm{dL}$; hematocrit $31.3 \%$; WBC count $6,410 / \mu \mathrm{L}$; platelet count $551,000 / \mu \mathrm{L}$; iron $11 \mu \mathrm{g} / \mathrm{dL}$; ferritin $4 \mathrm{ng} / \mathrm{mL}$; TIBC $354 \mu \mathrm{g} / \mathrm{dL}$; TS $3.1 \%$; total protein $6.2 \mathrm{~g} / \mathrm{dL}$; albumin $3.9 \mathrm{~g} / \mathrm{dL}$; CRP $0.09 \mathrm{mg} / \mathrm{dL}$; and ESR $5 \mathrm{~mm} / \mathrm{h}$. His FIT was negative, and FC level was $331 \mathrm{mg} / \mathrm{kg}$. EGD showed diffuse mucosal nodularity, active ulcers and scars. Histology of the gastric mucosal biopsy showed irregularly thickened subepithelial collagenous bands measuring $60 \mu \mathrm{m}$ in the stomach antrum, body, and pylorus (Figure $2 A$ ) and $50 \mu \mathrm{m}$ in the duodenum, which strongly stained with Massontrichrome (Figure 2B) but negative for amyloid with Congo red stain (Figure 2C). CLO test was negative. The gross appearance of the colonic mucosa on colonoscopy again showed no abnormalities. However, on random colonic biopsy from the cecum, ascending colon, transverse colon, descending colon, and sigmoid colon, subepithelial collagenous bands of $30 \mu \mathrm{m}$ were observed in all biopsy specimens (Figure 3).

He was diagnosed with $C G$ with concurrent CD and collagenous colitis. He started treatment with lansoprazole and oral iron supplementation was continued. Further serum immunological tests, including antinuclear antibody, anti-smooth muscle antibody, and antibodies to autoimmune diseases commonly observed in adult-type CG, were all negative.

Treatment with lansoprazole and oral iron supplementation was continued for a year. However, his IDA had not improved (Table 1). Follow-up EGD conducted one year after the diagnosis of CGDC, showed improvement of previously observed active ulcers and scars, while diffuse nodularity, and mucosal erythema and erosions were continuously observed. Follow-up colonoscopy repetitively showed no endoscopic abnormality. Histology again revealed collagen deposits with chronic inflammation in the stomach, duodenum and colon.

There were no significant changes in findings at the second- and third-year follow-up. To treat his IDA that did not improve by continuous treatment with lansoprazole and continuous iron supplements, systemic corticosteroids were attempted between the second- and third-year follow-up. However, two months treatment with oral prednisolone was not effective.

He has been followed for three and a half years. He currently does not have symptoms of abdominal pain and diarrhea. Despite continuous treatment with lansoprazole and oral iron supplementation, his IDA has not shown a 
Table 1 Laboratory results of the patient over time

\begin{tabular}{|c|c|c|c|c|c|c|}
\hline Laboratory tests & $\begin{array}{l}\text { Initial diagnosis of } \\
\text { IDA, } 3 \text { years before } \\
\text { visit (11-year-old) }\end{array}$ & $\begin{array}{c}\text { Initial visit } \\
\text { (15-year-old) }\end{array}$ & $\begin{array}{l}\text { At diagnosis of } \\
\text { CGDC } \\
\text { (16-year-old) }\end{array}$ & $\begin{array}{c}\text { One year after } \\
\text { diagnosis of CGDC } \\
\text { (17-year-old })\end{array}$ & $\begin{array}{c}\text { Two years after } \\
\text { diagnosis of CGDC } \\
\text { (18-year-old) }\end{array}$ & $\begin{array}{c}\text { Three years after } \\
\text { diagnosis of CGDC } \\
\text { (19-year-old) }\end{array}$ \\
\hline Hemoglobin, g/dL & 7.2 & 9.8 & 9.3 & 8.7 & 9.2 & 10.3 \\
\hline Hematocrit, \% & 25.0 & 32.9 & 31.3 & 30.8 & 30.0 & 35.7 \\
\hline $\mathrm{MCH}, \mathrm{pg}$ & 17.4 & 19.0 & 18.1 & 17.6 & 18.0 & 17.8 \\
\hline Platelet count, $/ \mu \mathrm{L}$ & 465,000 & 357,000 & 551,000 & 461,000 & 434,000 & 461,000 \\
\hline Iron, $\mu \mathrm{g} / \mathrm{dL}$ & 12 & 10 & 11 & 11 & 11 & 16 \\
\hline Ferritin, ng/mL & 2 & 5 & 4 & 3 & 3 & 4 \\
\hline Total protein, g/dL & 6.7 & 6.4 & 6.2 & 6.2 & 6.7 & 6.3 \\
\hline Albumin, $\mathrm{g} / \mathrm{dL}$ & 4.1 & 3.9 & 3.9 & 4.1 & 4.0 & 3.9 \\
\hline Globulin, g/dL & 2.6 & 2.5 & 2.3 & 2.1 & 2.7 & 2.4 \\
\hline $\mathrm{ESR}, \mathrm{mm} / \mathrm{h}$ & NA & 32 & 5 & 3 & 9 & 7 \\
\hline CRP, mg/dL & NA & 0.25 & 0.09 & 0.07 & NA & 0.08 \\
\hline $\mathrm{FC}, \mathrm{mg} / \mathrm{kg}$ & NA & 573 & 331 & NA & NA & 674 \\
\hline $\mathrm{FIT}, \mathrm{ng} / \mathrm{mL}$ & NA & 357 & 53 & NA & NA & NA \\
\hline
\end{tabular}

IDA, iron defiency anemia; CGDC, collagenous gastroduodenocolitis; WBC, white blood cell; MCV, mean corpuscular volume; MCH, mean corpuscular hemoglobin; TIBC, total iron binding capacity; TS, transferrin saturation; ESR, erythrocyte sedimentation rate; CRP, C-reactive protein; FC, fecal calprotectin; FIT, fecal immunochemistry test; NA, not available.

remarkable improvement (Table 1).

This case report was approved by the Institutional Review Board (IRB) of Soonchunhyang University Bucheon Hospital (IRB number SCHBC-2021-01-021-001). All procedures performed in studies involving human participants were in accordance with the ethical standards of the institutional and national research committees and with the Helsinki Declaration (as revised in 2013). Written informed consent was obtained from the patient's parent or legal guardian for publication of this case report and accompanying images. A copy of the written consent is available for review by the editorial office of this journal.

\section{Discussion}

CG is a rare disease, characterized by marked subepithelial collagen deposition. The incidence rate of childhood-onset
CG has been estimated as 0.25 per 100,000 person-years, and its prevalence is 2.1 per 100,000 (14). In children, it usually occurs before adolescence and is approximately 1.6-4 times more frequent in females than in males $(14,17)$. The definite pathogenesis is yet to be elucidated. However, it is assumed that CG may occur due to an abnormal response to toxic or infectious stimuli, which results in chronic inflammation associated with abnormal collagen deposition and secretion from fibroblasts (2-4). The pathological features of CG must include the deposition of collagen bands thicker than $10 \mu \mathrm{m}$ in the subepithelial layer, and it is often accompanied by a chronic inflammatory infiltrate.

Traditionally, there are two phenotypes of CG, which are the pediatric-type and the adult-type. These phenotypes are classified according to the involved location in the gastrointestinal tract. Involvement of the pediatric-type CG is confined to the stomach, while the adult-type CG 
has concurrent involvement in the small or large bowel. Nodularity of the stomach body is the characteristic finding in pediatric-type CG. The size and number of nodularity depend on the severity of the inflammation (18). This typical nodularity is not the result of mucosal thickening, but due to the depressed mucosa surrounding the nodules (18). In the pediatric-type, symptoms include intractable anemia and predominant epigastric pain, dyspepsia and vomiting. Symptoms such as weight loss and diarrhea are not typical.

The anemia of pediatric-type CG is probably a result of these dilated capillaries leading to microscopic blood loss and/or decreased iron absorption $(2,14,18)$. A recent large pediatric cohort has provided evidence of positive FIH tests and presence of GI bleeding supporting the hypothesis that IDA results from GI blood loss rather than poor absorption (2). Meanwhile, another study suggested that IDA results from decreased iron absorption due to gastric hypochlorhydria or other mechanisms (14).

In contrast, adult-type CG occurs commonly with concurrent $\mathrm{CD}$ and/or CC, presenting with watery diarrhea. It is also frequently accompanied with other autoimmune conditions $(5,10)$. Colonoscopic findings of CC shows a relatively even distribution of inflammation and atrophic changes or edematous colonic mucosa with pseudopolyps in the colon $(18,19)$. Because of these differences, it has been suggested that the pathogenesis differs between the two phenotypes (20). However, recent studies have suggested that these two phenotypes should be conceived as a continuous disease spectrum rather than separate diseases, using the terms of CG with or without CG instead of pediatric-type and adult-type CG $(2,5,14)$.

CG with concurrent $\mathrm{CD}$ and/or CC is very rare, and to date there are 24 pediatric cases reported in case reports or in cohort studies (1,2,5-16) including this case (Table 2$)$. Recently, Beinvogl et al. have reported the largest cohort of CG in children of 40 patients (2). In this study, concurrent CD was noted in $7 / 40$ (17.5\%), CC in $3 / 40(7.5 \%)$ and ileitis in $1 / 40(2.5 \%)$. One patient $(2.5 \%)$ had involvement in the entire GI tract, who had been previously reported in a case report (13). In the second largest pediatric cohort of 15 CG patients reported by Käppi et al., CD was noted in $1 / 15(6.7 \%)$, and CC in $1 / 15(6.7 \%)$. Considering that approximately 120 cases of pediatric CG have been reported in literature, cases with pediatric CG with concurrent CD and/or CC comprises approximately $20 \%$ of the total cases with pediatric CG $(1,2,5-16)$. Cases of pediatric CGDC as in this case are even more scarce, and to our knowledge there are only five cases including ours, comprising approximately $4 \%$ of the total pediatric cases of CG $(5,8,9,13)$.

While, IDA, epigastric pain, and upper endoscopic and histologic findings were typical in our case, a suspicious preceding infection with $H$. pylori was a unique finding. There are only a few cases of patients diagnosed with CG after infection and successful treatment with $H$. pylori $(15,21,22)$. All patients were treated with triple therapy with amoxicillin, clarithromycin and proton pump inhibitor (PPI) for the eradication of $H$. pylori. Despite the absence of a definite diagnosis of $H$. pylori infection, our patient was treated with triple therapy. However, his symptoms did not improve. Hence, endoscopy was redone, and CG was diagnosed.

The association between CG and H. pylori infection is yet to be elucidated. However, it is known that the clinical outcome of $H$. pylori infection is highly variable owing to the diversity of microorganism virulence factors and the inflammatory response of the host $(22,23)$. H. pylori are also capable of binding to connective tissue proteins and induce the release of pro-inflammatory chemokines leading to an inappropriately upregulated inflammatory reaction, resulting in fibrosis and collagen deposition $(22,24)$. Despite these hypotheses, there are few reports related to H. pylori. Meanwhile, current evidence suggests that the vast majority of pediatric CG cases are not associated with H. pylori. $(2,14)$ Considering the relatively high prevalence of $H$. pylori in South Korea compared to Western countries, the concurrent finding of $H$. pylori and CG may be merely just a coincidence. Future large-scale studies are required to elucidate whether $H$. pylori possesses a risk for the development of CG.

An important lesson from this case would be the necessity of repeat endoscopies if symptoms are to persist. In this case CGDC was not initially diagnosed but was diagnosed on the second EGD and colonoscopy. Although endoscopic findings of the first EGD was suspicious for either $H$. pylori gastritis or CG, histology revealed findings of only chronic inflammation. No thickened subepithelial collagenous bands were detected. Massontrichrome stain was retrospectively conducted later after diagnosis. However, subepithelial collagenous bands were not detected. Follow-up upper and lower endoscopies were conducted 1-year later, after the new development of diarrhea and persistent intermittent abdominal pain for a year. This is when subepithelial collagenous bands were detected in the stomach, duodenum, and colon, and the patient was finally diagnosed with CGDC. This shows that 
Table 2 Reported pediatric cases of CG with concurrent CD and/or CC in English literature

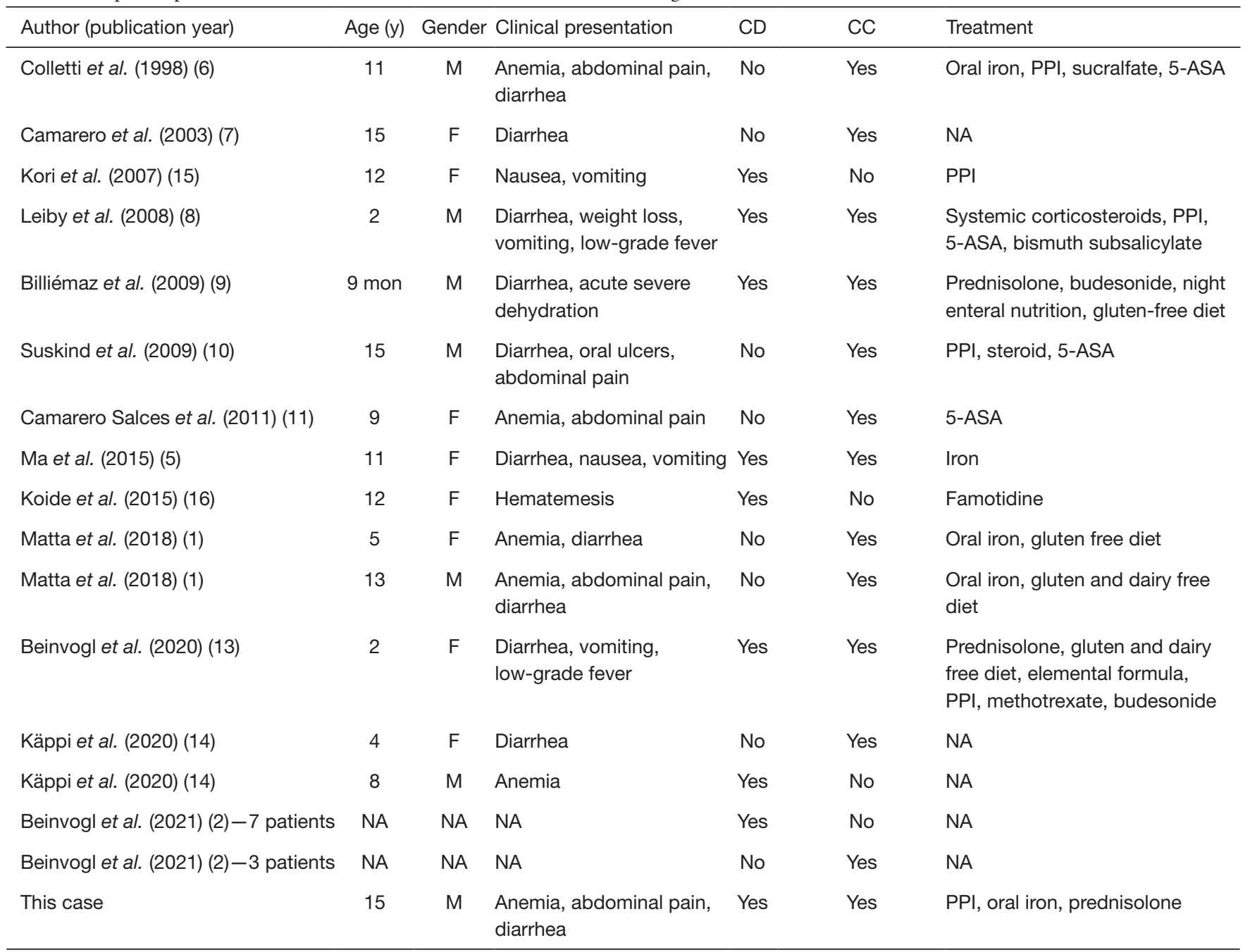

CG, collagenous gastritis; CC, collagenous colitis; CD, collagenous duodenitis; M, male; F, female; PPI, proton pump inhibitor; 5-ASA, 5-aminosalicylic acid; NA, not available.

initial histologic findings may be negative, and that repeat endoscopy is warranted if symptoms persist.

As the pathophysiology of CG is yet unclear, there is no obvious standard for the treatment of CG, and there is currently lack of efficient treatment (25). Several therapies have been attempted in CG patients, including corticosteroids, ranitidine, misoprostol, sucralfate, 5aminosalicylate acid, and hypoallergenic diets (7). It has been reported that among patients with CG with CC, few have experienced clinical, endoscopic, histologic improvement even after treatment with corticosteroids and azathioprine (1). Our patient started treatment with a PPI and oral iron supplementation for IDA. During follow-up for three years, his abdominal pain and diarrhea improved. However, his IDA and histologic findings have not shown improvement even after treatment with systemic corticosteroids.

Meanwhile, Winslow et al. (26) described the 12-year clinicopathologic evolution of CG in a single patient. Gastric corpus biopsy specimens revealed active chronic gastritis, subepithelial collagen deposition, smooth muscle hyperplasia, and mild to moderate glandular atrophy. Particularly, the patient's biopsy specimens showed a significantly lower number of antral gastrin cells, along with a significant corpus endocrine cell hyperplasia. These findings are suggestive of an increased risk of endocrine neoplasia, especially adenocarcinoma. Therefore, careful 
observation and follow-up is required in patients with CG.

Our case is the first to report CG with concurrent CD and $\mathrm{CC}$ in an Asian child. Children diagnosed with CG who present with lower GI symptoms such as diarrhea should also consider undergoing a colonoscopy for the evaluation of coexisting CC. Moreover, considering the possibility of negative findings on the first endoscopy, repeat endoscopy should be considered when symptoms persist. Furthermore, large scale longitudinal cohort studies are required in the future to better understand and reveal the pathogenesis of these collagenous diseases.

\section{Acknowledgments}

Funding: This work was supported by the Soonchunhyang University Research Fund (No. 20210021) granted to YML.

\section{Footnote}

Reporting Checklist: The authors have completed the CARE reporting checklist. Available at https://dx.doi. org/10.21037/tp-21-342

Peer Review File: Available at https://dx.doi.org/10.21037/ tp-21-342

Conflicts of Interest: All authors have completed the ICMJE uniform disclosure form (available at https://dx.doi. org/10.21037/tp-21-342). YML reports that this work was supported by the Soonchunhyang University Research Fund (No. 20210021) granted to her. The other authors have no conflicts of interest to declare.

Ethical Statement: The authors are accountable for all aspects of the work in ensuring that questions related to the accuracy or integrity of any part of the work are appropriately investigated and resolved. All procedures performed in studies involving human participants were in accordance with the ethical standards of the institutional and national research committees and with the Helsinki Declaration (as revised in 2013). Written informed consent was obtained from the patient's parent or legal guardian for publication of this case report and accompanying images. A copy of the written consent is available for review by the editorial office of this journal.

Open Access Statement: This is an Open Access article distributed in accordance with the Creative Commons
Attribution-NonCommercial-NoDerivs 4.0 International License (CC BY-NC-ND 4.0), which permits the noncommercial replication and distribution of the article with the strict proviso that no changes or edits are made and the original work is properly cited (including links to both the formal publication through the relevant DOI and the license). See: https://creativecommons.org/licenses/by-nc-nd/4.0/.

\section{References}

1. Matta J, Alex G, Cameron DJS, et al. Pediatric Collagenous Gastritis and Colitis: A Case Series and Review of the Literature. J Pediatr Gastroenterol Nutr 2018;67:328-34.

2. Beinvogl BC, Goldsmith JD, Verhave M. Pediatric Collagenous Gastritis: Clinical and Histologic Outcomes in a Large Pediatric Cohort. J Pediatr Gastroenterol Nutr 2021;73:513-9.

3. Freeman HJ. Collagenous mucosal inflammatory diseases of the gastrointestinal tract. Gastroenterology 2005;129:338-50.

4. Rustagi T, Rai M, Scholes JV. Collagenous gastroduodenitis. J Clin Gastroenterol 2011;45:794-9.

5. Ma C, Park JY, Montgomery EA, et al. A Comparative Clinicopathologic Study of Collagenous Gastritis in Children and Adults: The Same Disorder With Associated Immune-mediated Diseases. Am J Surg Pathol 2015;39:802-12.

6. Colletti R, Cameron D, Hassall E, et al. Collagenous gastritis: An international puzzle. J Pediatr Gastroenterol Nutr 1998;26:540.

7. Camarero C, Leon F, Colino E, et al. Collagenous colitis in children: clinicopathologic, microbiologic, and immunologic features. J Pediatr Gastroenterol Nutr 2003;37:508-13.

8. Leiby A, Khan S, Corao D. Clinical challenges and images in GI. Collagenous gastroduodenocolitis. Gastroenterology 2008;135:17-327.

9. Billiémaz K, Robles-Medranda C, Le Gall C, et al. A first report of collagenous gastritis, sprue, and colitis in a 9-month-old infant: 14 years of clinical, endoscopic, and histologic follow-up. Endoscopy 2009;41 Suppl 2:E233-4.

10. Suskind D, Wahbeh G, Murray K, et al. Collagenous gastritis, a new spectrum of disease in pediatric patients: two case reports. Cases J 2009;2:7511.

11. Camarero Salces C, Enes Romero P, Redondo C, et al. Collagenous colitis and collagenous gastritis in a 9 year old girl: a case report and review of the literature. Acta 
Gastroenterol Belg 2011;74:468-74.

12. Arnason T, Brown IS, Goldsmith JD, et al. Collagenous gastritis: a morphologic and immunohistochemical study of 40 patients. Mod Pathol 2015;28:533-44.

13. Beinvogl BC, Goldsmith JD, Arumugam R, et al. Pediatric Collagenous Gastroenterocolitis Successfully Treated with Methotrexate. Case Rep Pediatr 2020;2020:1929581.

14. Käppi T, Wanders A, Wolving M, et al. Collagenous Gastritis in Children: Incidence, Disease Course, and Associations With Autoimmunity and Inflammatory Markers. Clin Transl Gastroenterol 2020;11:e00219.

15. Kori M, Cohen S, Levine A, et al. Collagenous gastritis: a rare cause of abdominal pain and iron-deficiency anemia. J Pediatr Gastroenterol Nutr 2007;45:603-6.

16. Koide T, Mochizuki T, Kawai N, et al. Collagenous gastroduodenitis with recurrent gastric ulcer in 12-yearold girl. Pediatr Int 2015;57:754-7.

17. Nielsen OH, Riis LB, Danese S, et al. Proximal collagenous gastroenteritides: clinical management. A systematic review. Ann Med 2014;46:311-7.

18. Kamimura K, Kobayashi M, Sato Y, et al. Collagenous gastritis: Review. World J Gastrointest Endosc 2015;7:265-73.

19. Park S, Kim DH, Choe YH, et al. Collagenous gastritis in a Korean child: a case report. J Korean Med Sci

Cite this article as: Kang B, Um SH, Yun J, Kim HK, Choe BH, Lee YM. Collagenous gastroduodenocolitis in a Korean adolescent: first pediatric case report in Asia. Transl Pediatr 2021;10(11):3096-3103. doi: 10.21037/tp-21-342
2005;20:146-9.

20. Rosell-Camps A, Riera-Llodrá JM, Colom-Segui M, et al. Collagenous gastritis in the pediatric age. Rev Esp Enferm Dig 2015;107:313-5.

21. Dray X, Reignier S, Vahedi K, et al. Collagenous gastritis. Endoscopy 2007;39 Suppl 1:E292-3.

22. Vinsard DG, Mejia Perez LK, Nassar A, et al. Collagenous Gastritis and Helicobacter pylori Infection: A Mere Coincidence? ACG Case Rep J 2017;4:e69.

23. Hussain SA, Hamid S. Helicobacter pylori in humans: Where are we now? Adv Biomed Res 2014;3:63.

24. Krzysiek-Maczka G, Targosz A, Ptak-Belowska A, et al. Molecular alterations in fibroblasts exposed to Helicobacter pylori: a missing link in bacterial inflammation progressing into gastric carcinogenesis? J Physiol Pharmacol 2013;64:77-87.

25. Hijaz NM, Septer SS, Degaetano J, et al. Clinical outcome of pediatric collagenous gastritis: case series and review of literature. World J Gastroenterol 2013;19:1478-84.

26. Winslow JL, Trainer TD, Colletti RB. Collagenous gastritis: a long-term follow-up with the development of endocrine cell hyperplasia, intestinal metaplasia, and epithelial changes indeterminate for dysplasia. Am J Clin Pathol 2001;116:753-8. 